ESAIM: PROCEEDINGS AND SURVEYS, March 2015, Vol. 50, p. 66-80 Franck BOYER, Thierry GALLOUET, Raphaèle HERBIN and Florence HUBERT Editors

\title{
FEEDBACKS ON MOOCS
}

\author{
Marc Buffat $^{1}$, Alain Mille ${ }^{2}$ and Marco Picasso ${ }^{3}$
}

\begin{abstract}
This article contains the three contributions of the mini-symposium about MOOCs (Massive Open Online Courses) organized by Violaine Louvet (Institut Camille Jordan, CNRS). The first contribution is from Alain Mille from LIRIS, about the main research questions on this new way of learning. The second one is from Marc Buffat, LMFA. He reviews some open source Web ${ }^{2.0}$ computational environments which are used in a new MOOC on scientific computing. Marco Picasso, EPFL, is the author of the last contribution where he discusses the development of a MOOC in Numerical Analysis, before the MOOC, the course during the MOOC and the results. Many thanks to the authors who give a very interesting overview of the subject.

Résumé. Cet article contient les trois contributions du mini-symposium autour des MOOCs (Massive Open Online Courses) organisé par Violaine Louvet (Institut Camille Jordan, CNRS). La première contribution est due à Alain Mille, du LIRIS, et concerne les principales questions de recherche autour de cette nouvelle façon d'enseigner. La deuxième est proposée par Marc Buffat, du LMFA. Il dresse une revue de différents outils $W^{2.0}$ open-source, utilisés dans un MOOC sur le calcul scientifique. Marco Picasso, de l'EPFL, est l'auteur de la dernière contribution où il discute le développement d'un MOOC en analyse numérique, avant, pendant et après la tenue du cours. Remerciements aux auteurs qui nous offrent un très intéressant tour d'horizon du sujet.
\end{abstract}

\section{Moocs: new Research questions and methods, Alain Mille}

\subsection{MOOCs are in the context of the Web}

MOOC stands for Massive Open Online Courses. The challenge is to propose Online Courses for any public all around the world (Massive) in an Open world (the web). Online courses exist for a while, but usually they are focused on a specific public and are not so open. It is difficult to classify Moocs in clear categories, but it is usual to distinguish between $x$-Moocs and c-Moocs. c-Moocs stands for Connectivist Moocs and they were probably the first to be proposed (2008) The concept is described as a way to learn with pairs in an open collaboration. The collaboration is mediated by the Web [1]. If the c-Moocs were the first, the big success and popularity of Moocs comes from the category $x$-Moocs : there is no clear explanation about the $x$ which seems to come from the name of the EDx platform ${ }^{2}$ x-Moocs have a very different format than c-Moocs : the focus is given to videos with Quizzes and some other easy to evaluate exercises. The success of this kind of Moocs comes from the simplicity to join a course for anybody: a login, a password and an email address. Nothing has to be

\footnotetext{
${ }^{1}$ Université Claude Bernard Lyon I, Bat Omega (721) -2ème étage, 43 bd du 11 Novembre 1918, 69622 Villeurbanne Cedex

${ }^{2}$ LIRIS, Bat Nautibus (710), 43 bd du 11 novembre 1918, 69622 Villeurbanne Cedex

${ }^{3}$ Mathematics Institute of Computational Science and Engineering, Ecole Polytechnique Fédérale de Lausanne, 1015 Lausanne, Switzerland

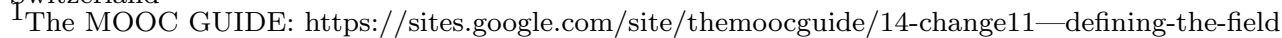

$2_{\text {https://www.edx.org/course-list/allschools/allsubjects/allcourses }}$
}

(C) EDP Sciences, SMAI 2015 
prepared, no big forms to fill, and so on. Big numbers of learners registered (160 000 for the first x-Mooc) but, of course, not such a number finished. Signing for a x-Mooc is exactly the same thing than signing for other services on the web (free access for the first level services). Learners do not feel to commit themselves when signing up for a course. Moreover, learners continue to use the web as they are used to do, with their usual tools. xMoocs turn to become open because of the web : blogs, web pages, open resources, collaborative tools, etc. are used besides the platform where the Mooc is delivered. This is an important point to understand: even when the Mooc platform is relatively closed, the Mooc is open for the learners. They organize themselves to build spaces where they can work together with usual web tools.

The learning process is flipped with regard of the classical one: the learner is the only one to build his learning goal, the teacher cannot give a unique learning goal. The learner choose the course, the teacher does not choose the learners. The learner can leave at any moment without referring to anybody, the teacher makes all his/her efforts to retain the learners. Before the course, the teacher with other people in charge of the design, can build a course with contents, activities and assessment mechanisms. During the Mooc, the learner has to try to find his/her way in this course and with the help of other learners, web resources and the ability to actively ask for information (forums, blogs, ...). Feedbacks are very important and, during the course, the Mooc team tries to provide it as soon it can understand what happens. Unfortunately, the current platforms are generally unable to provide a personal feedback to the learners, and useful analytics for the Moocs team. This is a big challenge for the research to be able to provide models, methodologies and tools to be able to give personal and just in time assistance during the learning process.

\subsection{Challenges for Technology Enhanced Learning Research}

The first challenge for researchers is to consider all what is known about Online Courses ${ }^{3}$ in the literature. Research has to focus on the specificities of a web oriented learning process. We try here to give some insights in the main research areas.

\subsubsection{Personalizing and adapting the learning process}

Personalization is not an easy job for a Mooc designer because he/she does not know how to interpret a very big variety of profiles. In an usual Online Course, either the number of learners is not very big and it is possible to begin the course by a first stage allowing to interact with the learners directly for adapting such or such thing, either the number of learners is very big and there is no selection process allowing to be confident with a priori profiles. Moocs count big numbers of learners, with very different profiles and goals. Moreover, it is not really possible to interact with them, individually. It is not really possible to consider standard profiles as working for this kind of public. A survey of the corresponding challenges is presented in 2:

- Web Integration : existing platforms (Coursera, EDx, Udacity, Future Learn, Iversity, Sakai, Moodle, ...) are on the web but do not really integrate the web as a resource by itself for organizing a Mooc. A lot of specific activities are proposed within the platform itself. It is almost impossible for the learner to manage his/her learning process when being outside the platform, while he/she uses extensively other services and resources of the web for his/her learning task. Giving the ability to assist the whole learning process, not only on the base of the learning activity on the platform, is a big challenge for the success of the Mooc approach.

- From content oriented design to learner oriented design : people have a big confidence in University to provide great contents and great science, and they are right. Courses have not to be designed for the general public but for any public. The difference is that learners do not ask for popular courses but for accessible courses. Any contents has to be proposed through interesting and adapted activities. The learner experience is the main challenge. This is a specific research topic in the domain of Information Architectures for learning.

- Technical and pedagogical support : A learner involved in a Mooc has to face both new concepts (knowledge) and new technologies (tools to be used on or outside the platform). The Mooc team has

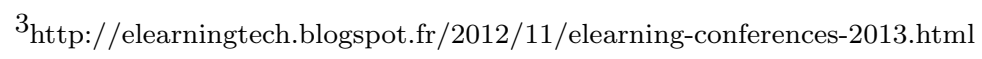


to prepare the learners and to assist them all along the learning process. The first session to learn how to learn on the platform is always present but often useless, because people want to begin the real course. Consequently, the assistance itself has to be dynamically adapted to the learner needs, and as it is impossible to provide it in real time by the team in charge of the Mooc, automatized assistance processes have to be designed and peer to peer approaches have to be integrated for capitalizing and sharing learner experiences. This is not a specific problem for Moocs, but as Moocs have a start date and an end date, dynamicity and agility are mandatory.

- Linking the learning process and the learner experience Many researches exist on the shelves about the way to take into account a learning profile for proposing and adapting learning activities. Building the profile in such a way it can be used to adapt the learning process for individuals (not for categories of individuals) is very difficult in the context of a Mooc. It seems almost impossible to do it without the help of the learner himself. To allow a learner to provide direct or indirect rules of adaptation and to provide relevant information for the profile is a new challenge in this well known research domain.

\subsubsection{Gaming}

In order to be able to capture the interest of a learner, it is usual to provide learning games for improving interest and attention. On the web, there is a lot of games, and they are familiar to a growing number of individuals in the society. A lot of works exist on the concept of learning games or serious games, and the research agenda for introducing games in the learning process has several common points with the research agenda about games on the web. Several challenges have been pointed in [3]:

- Gathering contributions of thousands of learners : gamers like to personalize their games and to share that with others. They become progressively co-designers of the game. Similarly, learners will like to co-design the learning games and it is perhaps a mandatory condition to provide a wide variety of learning situations with the same kind of game and for the same type of knowledge to learn (epistemologically speaking).

- Integrating body interactions : Accelerometers, cameras, microphones, GPS, tactile surfaces, voice commands, are now available for getting a better gamer experience. How to integrate them in the standard tools for designing a Mooc? Simulation is a great way to understand complex things, how to allow Mooc designers to provide simulation based activities in the most realistic way? How to adapt the designing process to allow teachers to use games in their activities?

- Pervasive games : How to integrate games with other activities, with other objects, with other resources on the Web. How to use the web 2.0 and the web of objects to link games with learning activities?

\subsubsection{Assessment and Engagement}

Assessment is an absolute necessity even when assessment is not used to certify the success of a learning process for an individual. Learners need assessments as feedbacks of their learning activity, and they are very interested to participate to the assessment process itself as a pedagogical activity. When the assessment is made in the context of a certification process, the Mooc's provider commits itself in the assessment process, and specific protocols have to be defined.

Engagement is a big challenge. Learners have to get a very nice experience of the learning process to commit themselves in the Mooc and to be active learners. Currently, the current engagement is not so big (10 to 20 percent) $]_{4}^{[}$and is often linked to an official certification. As stated in [4] about the assessment challenge and more generally about the engagement challenge, we can list the following issues:

- Semantics of digital badges: Moocs are providing a collection of badges about the knowledge level, but also and perhaps above all, about the learning behavior during the Mooc. The problem is to give an explicit semantic to these badges, able to be understood by the learner himself/herself, but more

\footnotetext{
${ }^{4}$ Mooc Completion Rates: the data http://www.katyjordan.com/MOOCproject.html
} 
generally in the society. As the source of most of these badges is the learning traces, the question of the traces semantics is pointed out too.

- Automated grading and scoring: if grading a quiz can be considered as easy, it is not the case for any open personal work. Several research works try to assess the value of dissertation ${ }^{5}$ (natural language). In the same way, several works try to assess the quality of a software source, of a diagram, and other semi-formal productions.

- Calibrated Peer Review: as said above, peer review can be considered as a pedagogical activity, but it appears that it can be a very good way for assessment purpose. Several encouraging researches, based on game theory for example, show that such an assessment can outperform the others if they are correctly calibrated and organized.

- Learning analytics for Assessment and Adaptive Learning: assessment is a kind of feedback for the learner and the Mooc team about the learning process. There is a special area of data analytics, named Learning Analytics which uses specific heuristics to analyze the learning traces (productions, logs, chronicles, ...) in order to discover some indicators useful to understand the learning process and able to guide adaptation (see section 1.2 .4 for more details). Adaptation can be made by the learner himself/herself or can be exploited by an adaptation process, considering these indicators as parts of the learner profile.

- Engagement Diagnosis and Remediation: this is probably one of the key of the success of a Mooc. How to recognize very early in the course what to do to keep a high level of commitment of learners in the Mooc? How to remediate very quickly when the commitment is lower? How to involve the learner himself to gather the conditions of his/her commitment?

\subsubsection{Learning Analytics}

The concept of learning analytics takes a specific sense when the context is Open Learning on the Web [5]. This point is defended by Eric Duva ${ }^{6}$. The challenges are numerous:

- One has to be able to observe the learning process far beyond the logs of the Mooc platform. Observing the learning activity needs the learner collaborates to the observation process, and to the analysis process.

- It is mandatory to to consider the privacy of the interactions traces. Learners traces are sensitive because they exhibit personal cognitive capabilities. These data are considered as sensitive as medical data. Specific precautions have to be taken when managing such private data.

- Useful indicators measuring different facets of the learning process have to be discovered from the learners traces, as well for assistance purpose as for discovering more general knowledge on the learning process during a Mooc. Numerous learning indicators have been proposed in literature but they have to be re-factored for the Mooc context and new ones have to be proposed for this specific context (engagement for example).

- Considering interaction traces as specific objects with specific methods to build progressively and explicitly new interpretations according to various points of views. 7

\subsubsection{New kinds of learning activities}

There exists a huge number of tools to build learning activities 8 and, for example, there exists a very interesting french web site to help On Line Learning Design: THOT ${ }^{9}$ The challenge is to adapt these tools and to invent new ones for the specific context of the Moocs [6]:

\footnotetext{
${ }^{5}$ https://www.ets.org/research/topics/as_nlp/

${ }^{6} \mathrm{http}: / /$ www.youtube.com/watch?v=LfXDzpTnvqY

${ }^{7}$ http://prezi.com/dn3fgdcdcvfv/?utm_campaign=share\&utm_medium=copy\&rc=ex0share

${ }^{8} \mathrm{~A}$ list of 2000 tools: http://c4lpt.co.uk/directory-of-learning-performance-tools/

$9_{\text {http://cursus.edu/ }}$
} 
- Self Directed Activities ${ }^{10}$ Self Directed Learning views learners as responsible owners and managers of their own learning process. In Self Directed Learning, control gradually shifts from teachers to learners.

- Cognitive, social, teacher presences: a big challenge is to give continuous feedbacks to the learner on his/her own cognitive presence (learning awareness), on his/her social context (who is present on the same activity, who is ok to give assistance, ...) and, of course, the availability of the teacher to provide explanations, help and other services. As a Mooc is a short and dynamic course, this has to be built quickly and with the help of all the Mooc's actors. Models of Presence have to be proposed accordingly to the dynamicity of a Mooc.

- Allowing learners to become teachers: This is a key point to invite the learners to commit themselves in the learning process. The best way to learn deeply is to teach what we try to learn. A new kind of platform has to be developed to give the same tools to the learner as to the teacher. From this point of view, the Claroline Connect ${ }^{11}$ Platform is particularly well suited to take up this challenge.

\subsection{CNRS Pilot in Lyon: COAT}

In Lyon, we tried to develop tools in order to be able to observe living Moocs. Moreover, these Moocs have been designed to give the learners the control of the observation and the ability to collaborate to the analysis process. A description of this approach is available on slideshare ${ }^{12}$ We applied a Design Oriented Research method which is described in Figure 1. A variety of assistance modules have been developed as well and are the target of near future scientific and technical contributions.

\footnotetext{
${ }^{10} \mathrm{http}: / /$ www.education.com/reference/article/Ref_Self_Directed/

${ }^{11}$ http://www.claroline.net/

${ }^{12} \mathrm{http}: / /$ fr.slideshare.net/aaamille/observing-learning-activity-traceme
} 


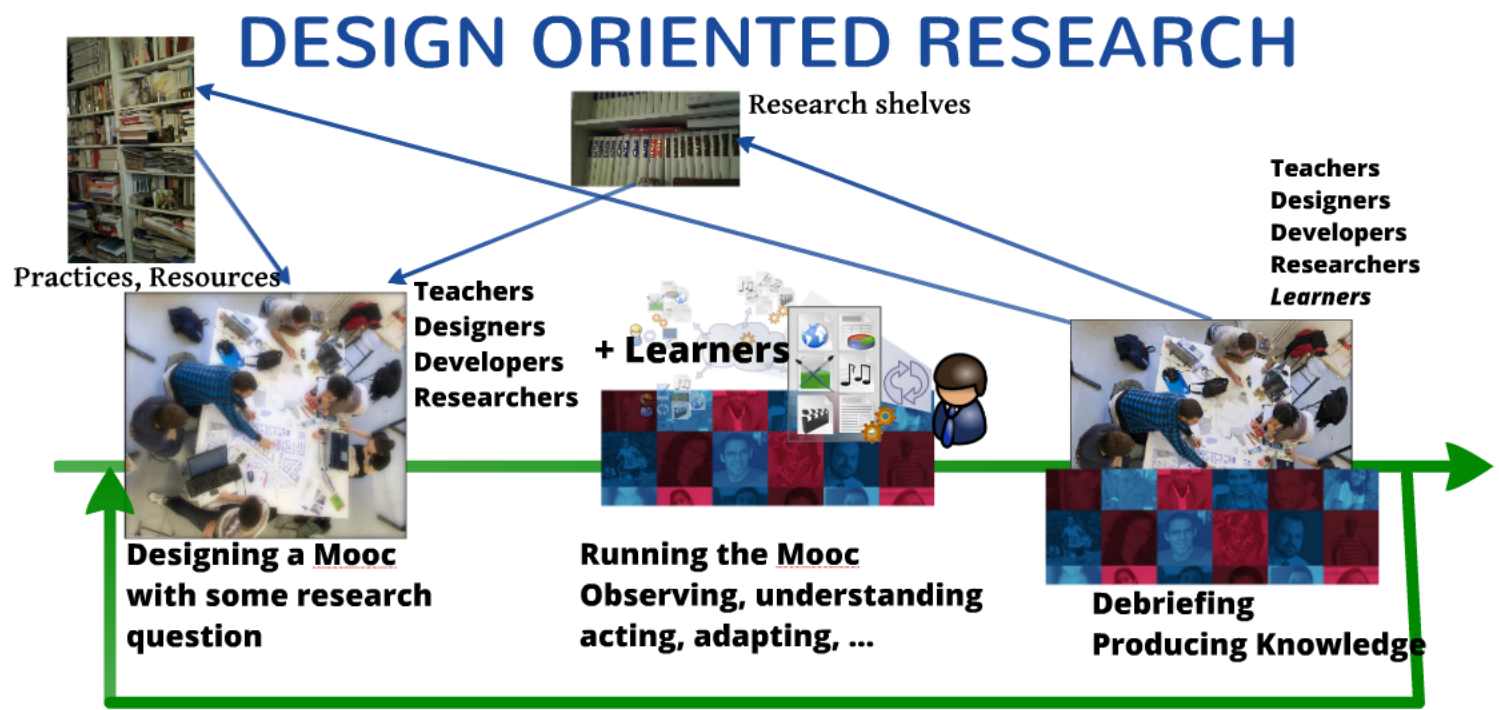

FiguRE 1. The design oriented research cycle: researchers, teachers, engineers are working together to design a Mooc, researchers propose to integrate knowledge and tools coming from the research shelves; during the Mooc, the whole team is involved and learners are invited to participate to the observation of the learning process, and this observation is directly visible during the learning process; after the Mooc, a debriefing stage allows to start new learning analytics with the help of learners volunteers; the next season of the Mooc can be designed by integrating the debriefing knowledge and by associating the learners to the process.

The general tools for observing and analyzing interaction traces is TRACE-ME ${ }^{13}$ and SAMOTRACE-ME ${ }^{14}$ These tools used the general framework kTBS 4 . Figure 2 gives a general idea of the learner experience of his/her own trace.

\footnotetext{
${ }^{13}$ https://github.com/fderbel/Trace-Me

${ }^{14}$ https://github.com/fderbel/Assistant-Samo-Trace-Me

${ }^{15} \mathrm{http}: / /$ kernel-for-trace-based-systems.readthedocs.org/en/latest/
} 


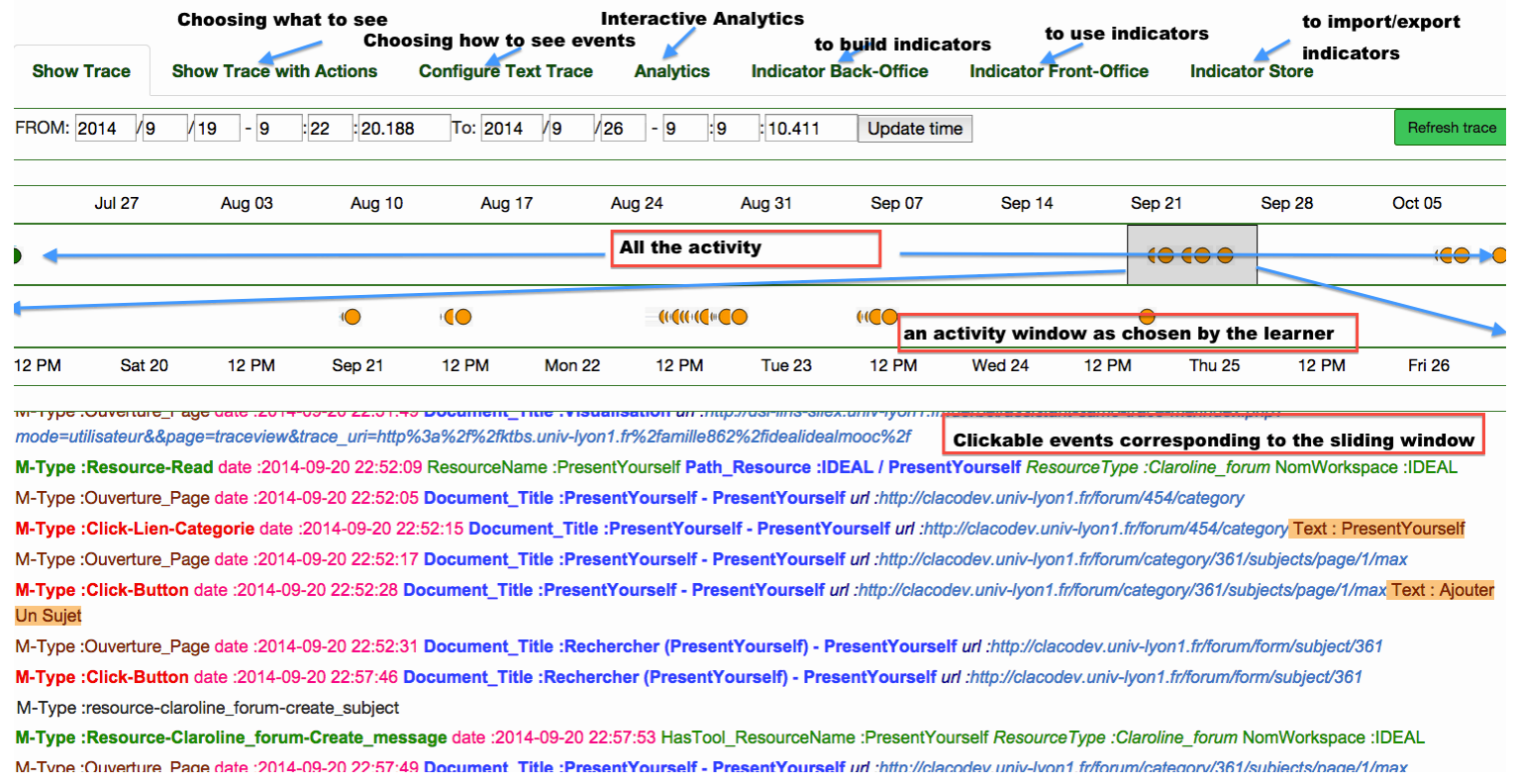

Figure 2. Personal assistant for managing learner traces

As a conclusion, we can say that research on Moocs renews existing research by considering the learner as the main actor of the learning process in a rich web environment. Multidisciplinary researches need a Design Oriented Research method and new ways to observe the learning process with the active participation of the learner.

\section{About the use of Webwork, SageCell and IPython notebook for teaching MATHEMATICS AND COMPUTATIONAL SCIENCE, MARC BufFat}

\subsection{Introduction}

Nowadays, numerical modeling, computer simulation and high performance computing have become essential tools for research and innovation. However the current training at the university does not adequately prepare the students to master these new tools, as it has been shown in a recent report of the "Conseil Stratégique pour le Calcul Intensif" (O. Pironneau 2013). In particular, the initial training of undergraduate students is inadequate (or non-existent) for mastering the scientific, mathematical and associated programming tools needed by high performance computing. Indeed mastering of scientific programming require the students to write computer programs and to do math exercises. At the Mechanical Engineering department of the University Claude Bernard Lyon 1, the on-line homework system Webwork [7 is used for many years for math and sciences courses, as well as the Python computer language and a Sage server 9 for learning scientific programming.

With this experience, we start in 2014 a project of a MOOC on scientific programming with our colleagues in the mathematics department of Lyon 1, University Joseph Fourier,Paris Sud and INRIA. The goal of this MOOC InProS 10] "Introduction à la programmation scientifique" is to teach a methodology for scientific programming, based on problem solving using Python and IPython notebook and on-line exercises using SageCell and Webwork. 


\subsection{WebWork}

WeBWorK 7 is an open-source online homework system with automatic correction and grading for math and science courses developed and maintained by mathematicians at the Rochester University since 1994. At the Mechanical Engineering department, we use Webwork since 2006 to assign homework problems to students in calculus, numerical methods, finite-element, solid and fluid mechanics [8]. Different parameters for each problem are selected for each student to allow students to work together but ensure that each student completes his own work. Using the web server WebWork, students know immediately if they have solved a problem correctly and WeBWorK lets a student keep working until a problem is solved. Home-work grading represents between $10-20 \%$ of the course grade and we got an extremely positive feedback from the students.

\subsection{Python, Sage and SageCell}

Historically in the mechanical engineering department, we used the numerical computing environment Matlab to teach numerical methods, because of its ease of use for beginners and the large amount of available toolboxes. However, Matlab is not a real programming language and students tended to learn only how to write Matlab script using black-box libraries functions instead of learning scientific programing. In recent years, we start to use "Scientific Python" to teach scientific computing. Indeed Python is a beautiful programming language, with great readibility that makes it a good choice as a first programming language. With the scientific libraries (Nympy, Scipy and Matplotlib), it is a great alternative to Matlab to teach numerical methods.

To allow our students to use Python without installing the "Scientific Python stack" on their computer, we use a Sage web-server (http://sage-meca.univ-lyon1.fr), based on the free open-source mathematics software Sage [9. We also use a Sage cell-server, which is an open-source, scalable, and easy-to-use web interface to Sage, that allow to embed Sage computations into any web-page. The Sage cell server will be used in the MOOC InPros as an interactive activity while watching the video of the course, to allow the student to redo the examples described in the course (see Figure 3 on the left). It will also be used in the exercise section of the MOOC where the students write their own Python code inside a Sage-cell and then run a testing-code in the Sage-cell below to validate it (see Figure 3 on the left). 


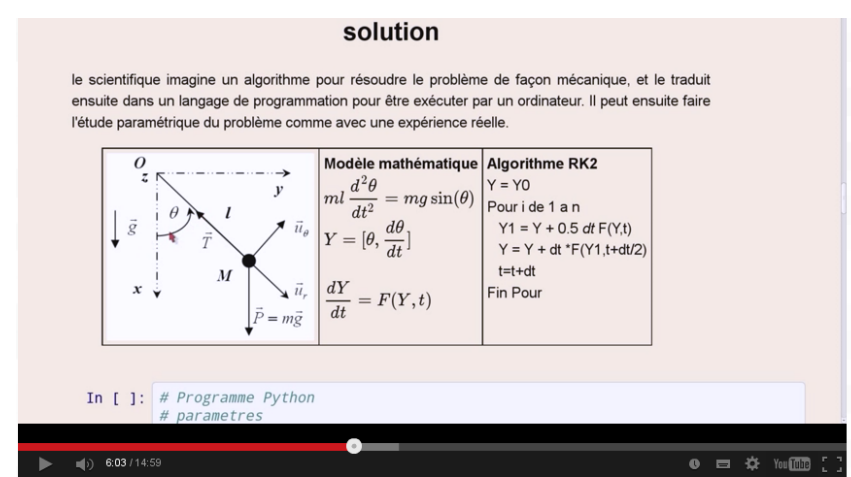

Cours au format PDF

cellule Sage pour tester le code Python

Tapez les exemples de code Python dans la cellule ci dessous et exécuter les en cliquant sur Executer.

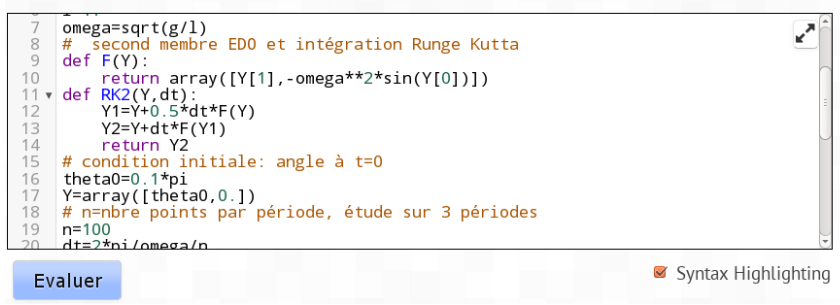

\section{Calcul de serie de Taylor de $\sin (x)$}

Écrire une fonction SerieSin(x,eps) qui calcule la valeur approchée $S_{n}$ de la limite de la série suivante avec une précision eps:

$S_{n}=\sum_{k=0}^{n}(-1)^{k} x^{1+2 k} /(1+2 k) !$

Exécuter le programme en cliquant sur Executer.

\begin{tabular}{|lll|}
\hline 1 & def SerieSin( $\mathbf{x}$, eps $):$ & \\
\hline Executer & 『 Syntax Highlighting \\
\hline
\end{tabular}

Puis valider votre programme, en cliquant sur Executer pour executer le programme de test. Si votre programme est correcte, le test affiche le message "Test OK", sinon vous avez un message d'erreur et vous devez corriger votre programme.

\begin{tabular}{|c|c|}
\hline $\begin{array}{l}1 \\
2 \\
3 \\
4 \\
5\end{array}$ & $\begin{array}{l}\text { \# Programme test } \\
\text { import numpy as np } \\
\text { for } x \text { in [0,np.pi/4,np.pi/2,-np.pi/4, -np.pid } \\
\text { np.testing,assert_almost_equal(SerieSin } \\
\text { print "Test OK" }\end{array}$ \\
\hline & Syntax Hig \\
\hline
\end{tabular}

Figure 3. SageCell inside the MOOC InPros activity

\subsection{Ipython notebook}

The IPython Notebook [11] is a web-based interactive computational environment where you can combine Python code execution, text, mathematics using $\mathrm{LAT}_{\mathrm{E}} \mathrm{X}$, plots and rich media into a single document. It is already used as a medium of instruction for courses in numerical methods or scientific computing as seen in the recent SciPy and PyconFR conferences [12,13.

In the MOOC InProS, we will used IPython Notebook as the main course material. Our main objective is to replace PowerPoint like presentation by a more dynamical presentation using live coding and demonstration. Furthermore, in order to have more engaging video, we combine screencast of the notebook using handwritten font and Khan academy style tutorial (i.e. using hand annotation with a digital tablet) (see Figure 4). A recent study on EdX online MOOC videos [14] show that informal presentation and Khan-style tablet drawings are more engaging for students than more formal PowerPoint slide presentation. 


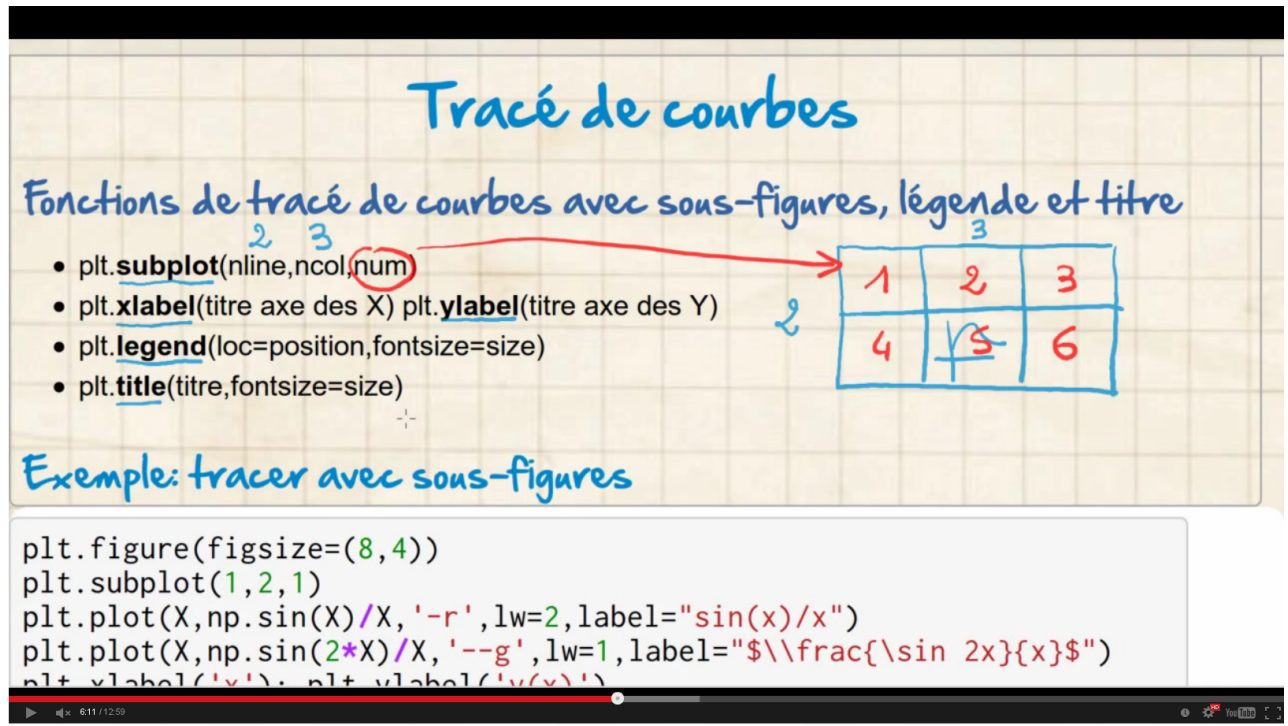

FIGURE 4. InProS video lesson using Ipython notebook and hand annotation with a digital tablet

Furthermore, the use of Ipython notebook allow us to produce, from the same material, an HTML version of the course for on-line viewing and a pdf version for hardcopy handout (see Figure 5).
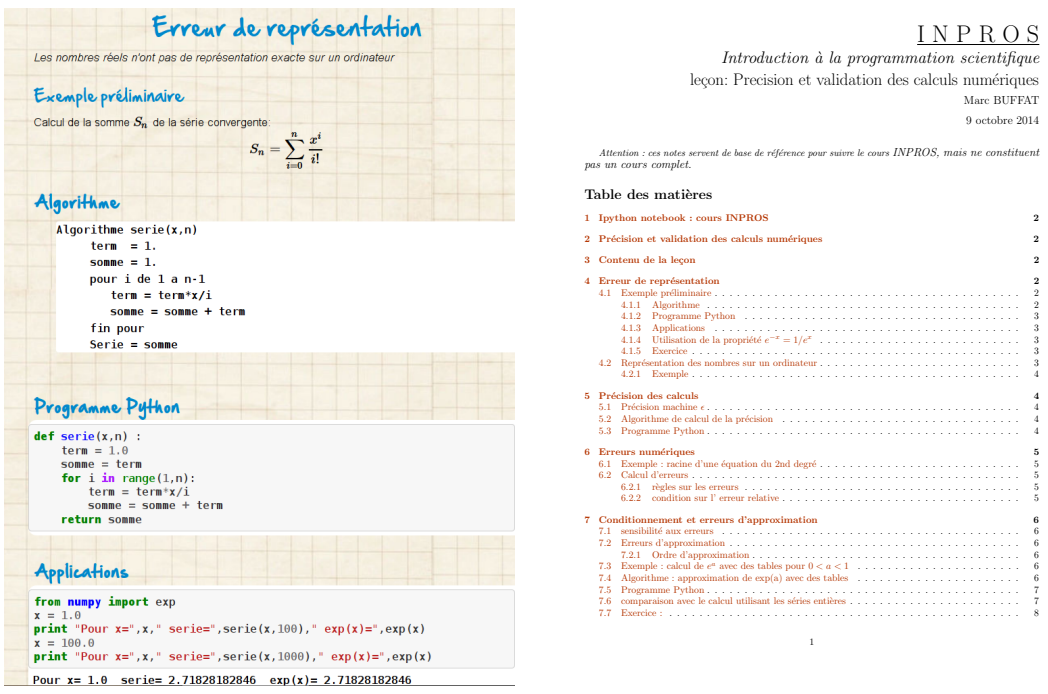

Figure 5. HTML (left) and pdf version of the IPython notebook for the InProS lesson

\subsection{Conclusion}

These three open source web base platforms (IPython notebook, Sage, WeBWork) have proved to be very useful tools for teaching mathematics and computational physics in our mechanical engineering department. 
And we are convinced that these tools can help to develop more interactive learning tools for MOOCs on computational science.

\section{About the Development of a MOOC in Numerical Analysis, Marco Picasso}

\subsection{Introduction}

Most EPFL Professors heard the first time about MOOCs in August 2012: Daphne Koller, Professor at the Stanford Artificial Intelligence Lab and co-founder of coursera, gave a talk to present MOOCs to the yearly meeting between EPFL Professors and the Direction. After the meeting, our President Patrick Aebischer, whois extremely enthousiastic about MOOCs, asked us: "Who would like to make a MOOC?" I thought to myself that my Numerical Analysis course to 400 non-mathematician Bachelor students would be a good candidate. However, I also thought that transforming it into a MOOC would be an enormous work...Thus, I did not raise my hand. You cannot always do what you want, the Direction asked me to make a MOOC, and I will describe hereafter how I did it.

The first EPFL MOOC was given by Martin Odersky, the designer of the Scala programming language, in September 2012. In February 2013, 4 MOOC were proposed by EPFL, and today EPFL is proposing 16 MOOCs on the coursera platform, 6 on edX, more than 10 being in French. EPFL has delivered more than 30 000 certificates around the world, while having 10000 students on campus.

\subsection{Which MOOC for who?}

The MOOCs produced at EPFL can be put in 3 categories:

- The unique MOOC: for instance the Scala MOOC given by Martin Oderski. Someone who needs a Scala MOOC is likely to choose the one given by the inventor of Scala. This MOOC has already been given 3 times with 50000 registrations per course and 10000 certificates delivered for each course. Such as course can be viewed as continuing education.

- The visibility MOOC: take a highly cited Professor and ask him to make a MOOC. This is the case of Martin Vetterli's MOOC Signal Processing.

- The teaching MOOC: choose a first year course having many students and tranform it into a MOOC. This is the case of Philippe Ansermet's MOOC "Mécanique I" or "Initiation à la programmation (en $\mathrm{C}++$ )" by Jean-Cédric Chappelier and Jamila Sam. My MOOC "Analyse Numérique pour ingénieurs" falls into this category.

\subsection{The old Numerical Analysis course}

This Numerical Analysis course, in its classic version, corresponds to the teaching book 15. The course is tought at EPFL at Bachelor level to first years students in physics, second year students in mechanics, third year students in computer science. The course corresponds to a 14 weeks semester, a chapter being presented each week. Numerical tools are presented the first 7 weeks: interpolation, difference formula, quadrature, linear systems, nonlinear systems. The remaining 7 weeks correspond to solving ordinary differential equations and partial differential equations arising from physics and engineering.

Each weak, the ex-cathedra course is 2 hours on the blackboard, the exercice session 1 hour in a computer lab. During the exercice session, the students fill an incomplete Matlab/octave file and run numerical experiments to confirm the theoretical predictions. Proofs are also asked.

Concerning the workload, the official policy at EPFL is to have an hour of homework for one hour on campus. Students have between 25 and 30 hours per week on campus, they are supposed to work 50 to 60 hours in total. Thus my course has $2+1=3$ hours on campus, the students are supposed to work 6 hours in total. This workload should be maintained in the MOOC. 


\subsection{The new Numerical Analysis MOOC}

Only the first 7 weeks of the course are included in the MOOC:

- Week 1: interpolation,

- Week 2: finite difference formula,

- Week 3: numerical quadrature,

- Week 4: solving linear systems,

- Week 5: solving nonlinear systems,

- Week 6: solving ordinary differential equations,

- Week 7: solving boundary value problems in 1D using finite difference methods,

- Week 8: final exam.

The remaining weeks (9 to 14) are classical: ex-cathedra course on the blackboard, exercices in the lab.

The material contained in a 2 hours ex-cathedra course is written and recorded on a 24 inch tablet. A 2 hours course is replaced by 6 times 10 minutes video, the tablet being filled after each 10 minutes video, see Fig. 6. After each video, the student is asked to fill a 10 minutes quiz in order to check his understanding, see Fig. 7. Thus, after having repeated 6 times 10 minutes video plus 10 minutes quiz, the equivalent of the 2 hours ex-cathedra course has been presented.

It remains to complete the so-called "homework quiz" which corresponds to filling an incomplete Matlab/octave file, running (on the student's computer) numerical experiments and filling a quiz on the coursera platform. EPFL students have the possibility to perform this homework quiz in a computer lab under the guidance of assistants (master or PhD students).

Finally, a proof is asked, see Fig. 8, the so-called "peer assessments" on the coursera platform: students upload their hand-written sheet; the week after, the official solution appears online and each student must grade three other students. During the first session of the MOOC (Feb 2013), the sheets of EPFL students were corrected by a teaching staff (Master students in mathematics), which took too much time. Therefore, during the second session (Feb 2014), I proposed each week an hour of flipped classroom with the students in order to solve this theoretical question.

A forum allows students to interact each other and to ask questions to the teaching staff. EPFL students do not use very much this forum, it is mainly used by off campus students.
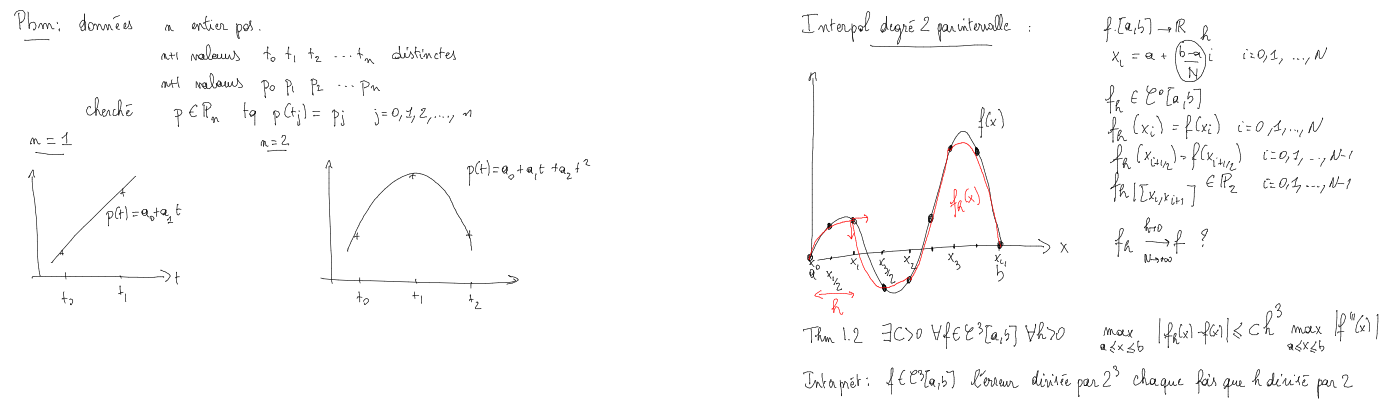

Figure 6. Two slides corresponding to two videos of chapter 1 (interpolation). Left: first video, right: last video. 


\subsection{Grading and analytics}

The grading is the following. The quizzes give $20 \%$ of the grade, the homework quizzes $30 \%$, the final exam $50 \%$. The certificate is obtained when getting more than $60 \%$ of the grade, with distinction when getting more than $85 \%$. About 5000 students registered in each of the two sessions, 500 to 700 watched the videos, completed the quizzes and the homework quizzes each week.

For instance, during the second session of the MOOC, 242 students got more than $85 \%$ of the grade, 364 more than 60\%, 420 more than 30\%, 473 more than 10\%. About 50 off campus students got the certificate, 10 with distinction.

Concerning EPFL students, the MOOC's grade is considered as a midterm, 100\% of the MOOC's grade gives $1 / 6$, the remaining $5 / 6$ being obtained at the end of the semester.

\subsection{The students' opinion}

At EPFL, each course is graded by the students. In average, EPFL students recognized that this Numerical Analysis course was a good course to be "MOOCified". Some of them liked the fact that they could replay a video whenever needed.

However, during the first session of February 2013, some of the students argued that they did not come to EPFL to watch videos, rather to listen to Professors in classrooms. This was corrected in the second session of February 2014, flipped classrooms were introduced to solve the rather difficult peer assessments. The use of flipped classroom seems to be a successfull tendency in other teaching MOOCs at EPFL.

\section{Acknowledgements}

Marco Picasso would like to thank the staff of the MOOCs Factory Lab at EPFL, Patrick Jermann for technical support and Jérémy Rieder for cutting the videos. The scientific staff is also acknowledged, Gilles Steiner post-doc, Viljami Laurmaa PhD student and Giacomo Rosilho de Souza master student, all in the Section of mathematics.

\section{REFERENCES}

[1] McAuley, A., Stewart, B., Cormier, D. and Siemens, G, In the Open: The MOOC model for digital practice, SSHRC Application, Knowledge Synthesis for the Digital Economy, 2010, http://www.elearnspace.org/Articles/MOOC_Final.pdf

[2] Cemal Nat, Muesser, Dastbaz, Mohammad and Bacon, Liz , Research and design challenges for developing personalised eLearning systems., E-Learn 2008 Proceedings: World Conference on E-Learning in Corporate, Government, Healthcare, and Higher Education 2008, Ed/ITLib Digital Library, Association for the Advancement of Computing in Education (AACE), Chesapeake, VA, USA , 2008

[3] Palazzi, C.E., Roccetti, M. and Marfia, G., Realizing the unexploited potential of games on serious challenges, Revue, Computers in Entertainment, 8(4), pp.1-4., 2010, http://portal.acm.org/citation.cfm?doid=1921141.1921143

[4] Sandeen, C, Assessment's Place in the New MOOC World., Research and Practice in Assessment, 8(Summer), pp.5-12, 2013

[5] Liddo, A. De And Alevizou, P, A method and tool to support the analysis and enhance the understanding of peer-to-peer learning experiences, In OpenED2010: Seventh Annual Open Education Conference, Barcelona, Spain, 2010, Available at: http://openaccess.uoc.edu/webapps/o2/handle/10609/4941

[6] Kop, R., The challenges to connectivist learning on open online networks: Learning experiences during a massive open online course, The International Review of Research in Open and Distance Learning, 12(3), 2011, Available at: http://nparc.cistiicist.nrc-cnrc.gc.ca/npsi/ctrl?action=rtdoc\&an $=18150443$

[7] WeBWork, "système de devoirs de mathématiques en ligne" http://webwork. maa.org.

[8] M. Buffat, "WebWork un système de devoirs en ligne sous Moodle", Conférence MoodleMoot2009, INSA de Lyon Juillet 2009

[9] SAGE, "logiciel libre de mathématiques en ligne" http://www. sagemath.org.

[10] MOOC InProS, "Introduction à la Programmation Scientifique"|http://inpros. univ-lyon1.fr.

[11] IPython, "The IPython Notebook", http://ipython.org/notebook.html

[12] D. I. Ketcheson, A. Ahmadi, "Teaching numerical methods with IPython notebooks", Scipy 2014, https://conference. scipy.org/scipy2014/schedule/presentation/1672

[13] M. Buffat, "Ipython Notebook pour l'enseignement", conférence Python PyconFR, 25-26 Octobre 2014 
[14] P. Guo, J. Kim, R. Rubin, "How video production affects student engagement: an empirical study of MOOC videos", ACM conf. L@S '14, 2014

[15] Rappaz, Jacques and Picasso, Marco, "Introduction à l'analyse numérique", Enseignement des Mathématiques. [The Teaching of Mathematics], Reprint of the 1998 original, Presses Polytechniques et Universitaires Romandes, Lausanne, 2004. 